\title{
Assessing the impacts of implementing lean construction
}

\section{Evaluando los impactos de la implementación de lean construction}

\author{
Luis F. Alarcón*1, Sven Diethelm*, O scar Rojo*, Rodrigo Calderón* \\ * Pontificia Universidad Católica de Chile, Santiago, CHILE
}

Abstract

PAG. $26-33^{2}$

O ver the last 10 years an increasing number of companies have implemented lean construction practices in an attempt to improve performance in construction projects. Most companies, and also some researchers, have reported satisfactory results from their implementation. However, there is still a need to provide more extensive analysis of the empirical evidence available to assess the impact of the implementation of lean construction. The authors have researched the implementation of the Last Planner System and other Lean Construction techniques in over one hundred construction projects over the last five years. They have also developed strategies and support tools for implementation. This paper analyzes some of the main impacts observed in the studied projects, and some of the lessons learned from implementations. The paper discusses difficulties and barriers for implementation, productivity improvements, variability reduction and effectiveness of implementation strategies. The paper also provides recommendations for future implementation and research.

Keywords: Lean construction, implementation, last planner system, IT

Resumen

En los últimos 10 años un creciente número de empresas constructoras ha implementado prácticas de Lean Construction para mejorar el desempeño de sus proyectos. La mayor parte de estas empresas, y también algunos investigadores, han informado sobre buenos resultados obtenidos en los proyectos. Sin embargo, todavía es necesario un análisis más completo de la evidencia empírica disponible para evaluar así el impacto de Lean Construction en los proyectos y empresas. Los autores han investigado la implementación del Sistema U Itimo Planificador y otras técnicas de Lean Construction en mas de un centenar de proyectos en los últimos 5 años y han desarrollado estrategias y herramientas de apoyo para su implementación. Este artículo analiza algunos de los principales impactos observados en los proyectos estudiados y las lecciones aprendidas en este proceso. Se discuten dificultades y barreras para la implementación, mejoramientos de productividad, reducciones de variabilidad y efectividad de las estrategias de implementación. El artículo entrega también recomendaciones para implementación de Lean Construction y para futuras investigaciones.

Palabras Clave: Lean construction, implementación, sistema ultimo planificador, TI

\section{Introduction}

The implementation of lean construction practices emphasizing the Last Planner System (LPS) (Ballard and Howell, 1998) and waste reduction techniques in a large number of projects has provided empirical evidence that is analyzed in this paper in order to summarize some of the lessons learned from the implementation. The paper analysis is based on data obtained from the authors own implementation experience and also from case studies found in the Lean Construction literature (Koskela 2000, Ballard 2000, Benardes 2001).

The Production Management Center (GEPUC), from the Catholic U niversity of Chile, promotes long term research and implementation alliances among companies to pursue common goals. The companies undertake their improvement programs working as a group, around common

\footnotetext{
1 Autor de correspondencia / Corresponding author: Vicuña Mackenna 4860, Macul, Santiago. Chile. Teléfono: 5602354 4244, E-mail: Ialarcon@ing.puc.cl
}

topics and with a common work agenda, this allows collaborative sharing of problems and solutions to the individual processes of improvement. The collaborative work scheme includes different forms of interaction among the representatives of the companies and the GEPUC, all of them seek to achieve competence in the participants for the autonomous development of the implementation under way, once the specific research and implementation goals have been achieved. Some of the important activities developed under this scheme are Periodic Meetings, Workshops, Plenary Sessions and Site Visits by the researchers. Details on methodological aspects of the implementation can be found in (Alarcon et al., 2002a, 2002b).

A database of 77 Chilean projects, from 12

\footnotetext{
2 Agradecimientos / Acknowledgements: Best paper award

14th Annual Conference of the International Group for Lean Construction July 25-27 2006 - Santiago Chile
} 
companies, was used to analyze the impact of the introduction of the LPS on different aspects of project performance. The project sample included 39 low rise building projects, 15 high rise building projects, 11 heavy industrial projects and 12 light industrial construction. This information was collected during a research project carried out to develop implementation strategies for Lean Construction and to measure the impacts of those strategies. The analysis considered implementation of projects during a three year period, from 2001 to 2003 (Alarcon et al. 2002a, Calderon 2004). Several measures obtained during implementation are analyzed in the following paragraphs and the results are discussed providing some additional information on the context of the implementation.

\section{Reduction of variability in projects}

\subsection{Improvements in percent of planned assignments completed}

Figure 1 shows how the average Percent Plan Complete (PPC) of the projects under investigation increased over the three year period. These results can be attributed to a number of reasons. 1) Learning process: four companies that participated over the entire period became more experienced in the implementation and experimented continuous improvement in the PPC indicator. Particularly, one them increased its average PPC from 55\% in 2001 to $88 \%$ in 2003 . A second company increased its average PPC from 50\% in 2001 to $76 \%$ in 2003. 2) Experience accumulated by the GEPUC team: this allowed for quicker and more effective implementation of new companies that joined the projects in 2002 and 2003. 3) Support tools: a number of tools were developed to support implementation and were quickly adopted by the companies to ensure a more complete and effective implementation. The sample of projects in Figure 1 includes projects with different level of implementation of the LPS elements, therefore the conclusions drawn from the data should consider these aspect. 4) Top management involvement and understanding of the process.

\subsection{Influence of the level of implementation on project} PPC

In an effort to obtain a better understanding of the impacts of the implementation level, a sub-sample of 11 Chilean projects $(\mathrm{N})$ and 5 international projects (I) were examined in more detail (Figure 2). Most projects in this sub-sample were building projects, except projects N 8, N10 and N11 that were light industrial projects.

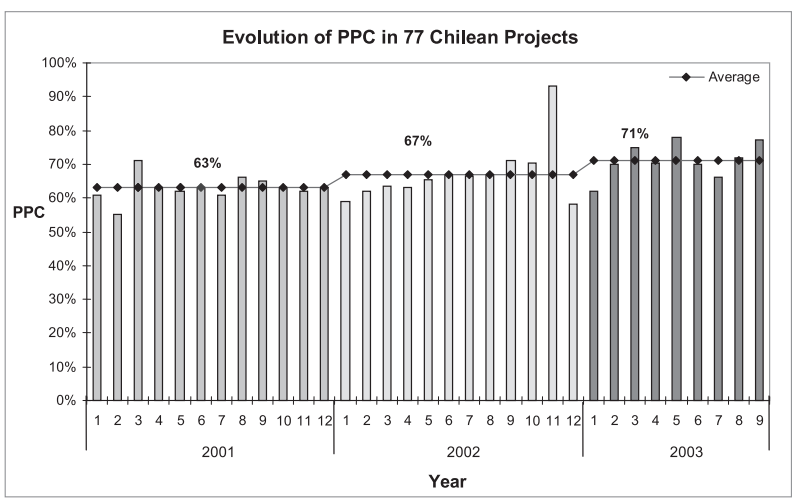

Figure 1. Evolution of PPC in a three-year period

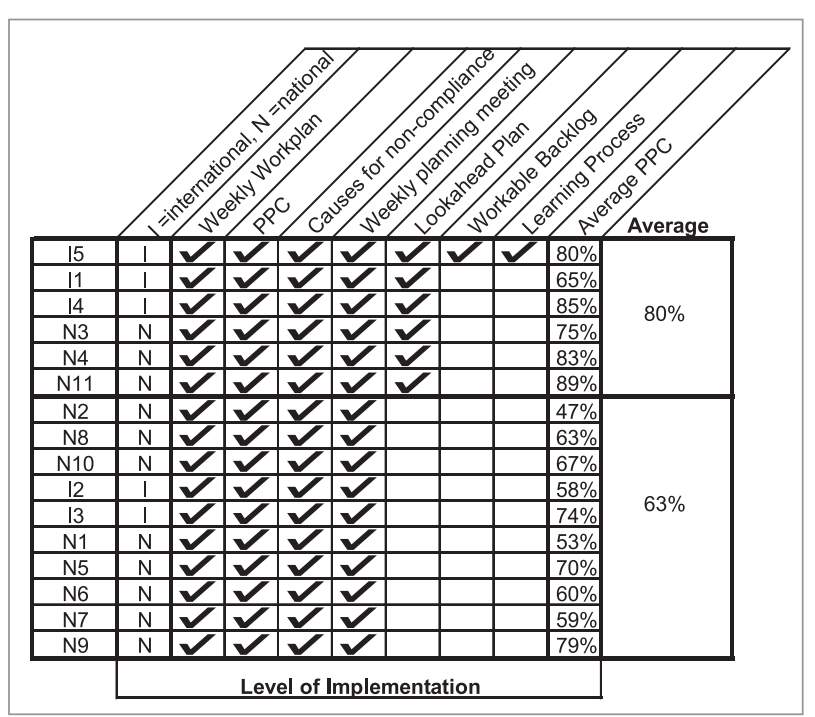

Figure 2. Impact of level of implementation on PPC performance

Figure 2 shows projects classified into two groups, according to the level of implementation of the LPS elements present in the projects. The first group consisted of 10 projects with a basic level of implementation with emphasis on the weekly work plan and only informal Lookahead planning. The second group included 6 projects that had implemented formal Lookahead planning process and in one case formal workable backlog and learning processes. The projects were also ordered according to their average PPC to facilitate the analysis. Figure 3 shows that, in general, projects with a more complete implementation had a higher PPC than projects with basic implementation.

\subsection{Causes for noncompletion in projects}

The analysis of causes for noncompletion in the full sample of projects provides interesting information. Initially, during the first year of implementation the causes 
for non-compliance were distributed over a large number of sources where only the first two, poor planning and field interference, were significantly more frequent than the others. At the end of the third year, the most important increase was observed in causes associated with subcontractors where this single item accounted for $24 \%$ of the causes. Poor planning and field interference also slightly increased their participation to $15 \%$. The fourth cause, poor planning of materials, accounted for $10 \%$ and was almost inexistent during the first year. M ost of the other causes decreased their participation during the third year.

A more detailed analysis was carried out by grouping projects with higher PPC and projects with lower PPC, as shown in Figure 4 and Figure 5. In both cases subcontractor delays were the most important cause for non-completion, however, in projects with PPC $>65 \%$ the relative importance of this cause is twice as much as the following cause in importance.

A general conclusion is that causes associated with external agents increased their participation, probably due to a better control of internal causes in the projects as they improved PPC. In projects with high PPC causes associated with the contractor's own management become less important in comparison with causes attributed to subcontractors. These causes increased in almost $200 \%$ during the period studied, but the percentage of contracts given to subcontractors also increased, explaining part of the effect.

\subsection{Variability of PPC measures}

O ne interesting result from the statistical analysis was the variability of PPC measures in projects. Figure 5 shows the relationship between average PPC and the coefficient of variation of the measures. These results are similar to those obtained by Benardes (2001) in a sample of Brazilian projects. It is clear that when PPC approaches $100 \%$ one should expect a coefficient of variation close to zero. However, this tendency is also observed in a range of lower PPC values. These means that projects with higher planning compliance also reach more stable PPC performance than projects with lower planning compliance. The practical implication is that PPC becomes more predictable as its value increases, providing a sense of control to the project team.

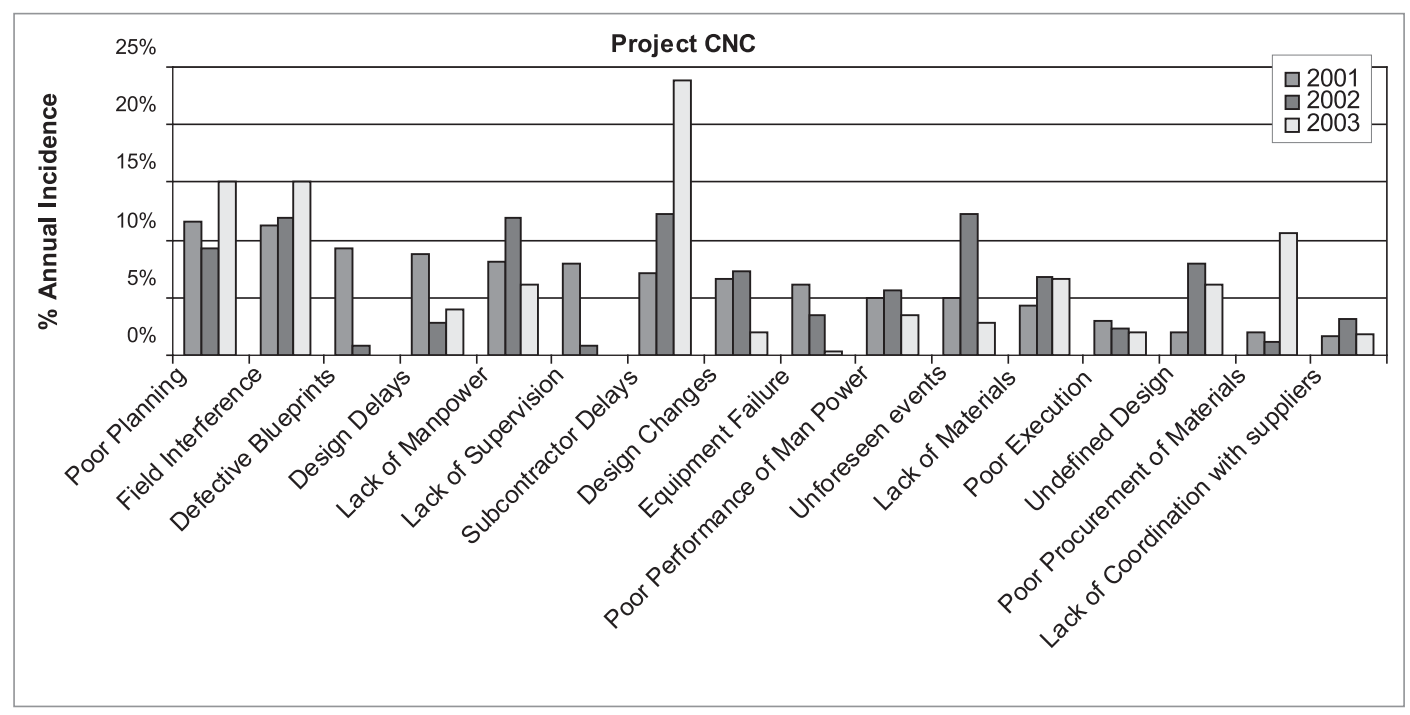

Figure 3. Evolution of causes for noncompletion in projects 




Figura 4. Causes for noncompletion in projects with PPC $>65 \%$

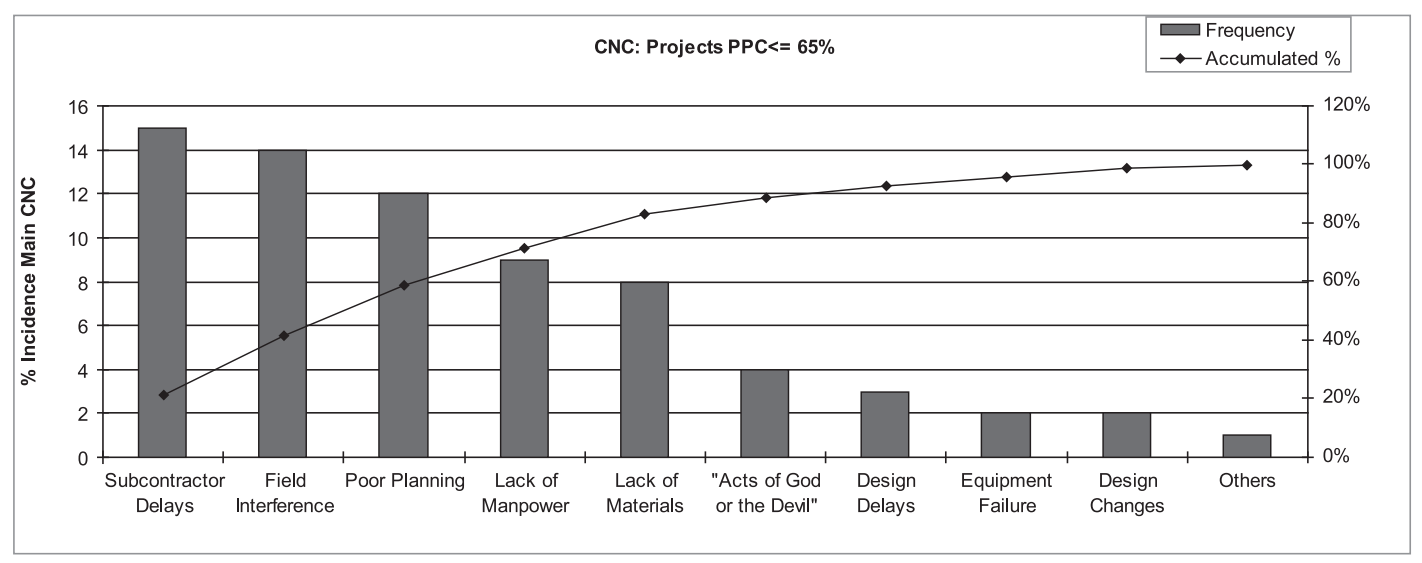

Figure 5. Causes for noncompletion in projects with PPC < 65\%

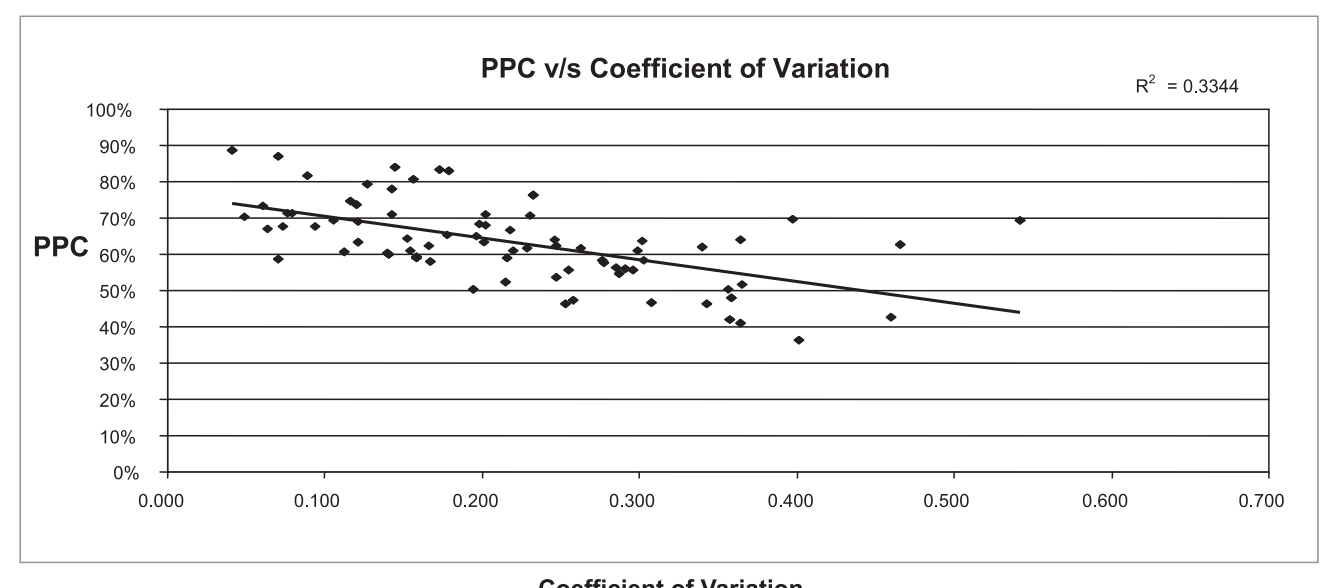

Coefficient of Variation

Figura 6. Relationship between average PPC and coefficient of variation 


\section{The impact of IT support on PPC performance}

The poor use of information generated during implementation of LPS was identified as the main barrier for a more complete implementation. Early in the project, the GEPU C team had attempted to introduce Workplan, a computer system developed by Choo (Choo et al, 1999) for LPS implementation. However, the companies did not feel comfortable using this system for similar reasons than those reported by (Choo et al., 2001). To break implementation barriers, the research team developed a prototype computer system working closely with the companies in a continuous interaction with them during system design. The prototype system, called "Plan Control" was tested in several projects (Alarcon and Calderon 2003). The main observed impact of this tool was a more complete implementation of the LPS in projects that used "Plan Control". These resulted in higher PPC performance for those projects that used IT support compared with projects without IT support.

Figure 7 shows two curves of the cumulative PPC frequency of projects with and without IT support. The curves can be interpreted as the project probability to reach a PPC performance over a value specified in the horizontal axis. For instance, a project without IT has a $21 \%$ probability to reach a PPC value of $80 \%$ or more. O $n$ the other hand, a project with IT support has a $39 \%$ probability to reach a PPC value of $80 \%$ or more. In general, projects with IT support have a higher probability to reach a certain PPC level than project without IT support. The data shows that the probability to reach high PPC values can be duplicated by using IT support for high levels of PPC performance.

\section{Performance improvements}

Performance improvements were measured quantitatively and qualitatively in a number of companies involved in implementation efforts. Figure 8 shows performance improvements reported by 8 different companies. These measures includes different performance indicators such as manpower productivity, cost factors, construction speed, schedule reductions, etc. Productivity improvements of up to $86 \%$ have been measured in individual projects (Alarcon et al., 2000).

Many companies had difficulties to accurately measure performance, however, in almost all the projects observed there were many perceived benefits from implementation. Q ualitative measures were obtained from surveys and questionnaires answered by members of the project teams involved in implementations. Figure 9 shows the benefits perceived. They cover a wide range of project management aspects including improvements in management and control, involvement of middle management, reduction of urgent procurement requests, and reductions in project schedule.

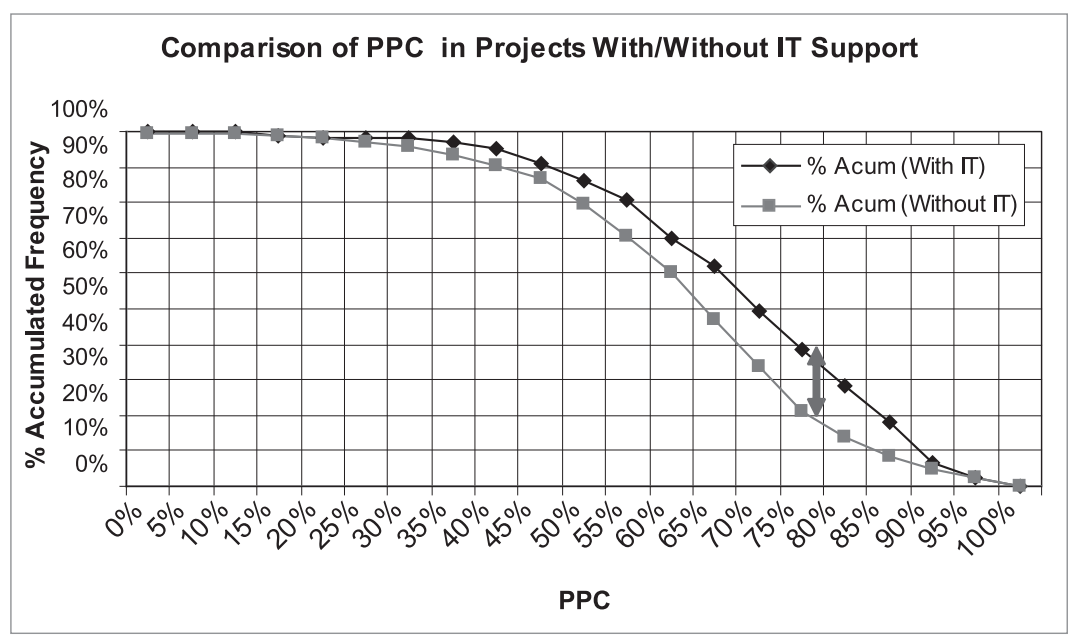

Figure 7. Probability of achieving a PPC higher than $X$ for projects with and without IT support 


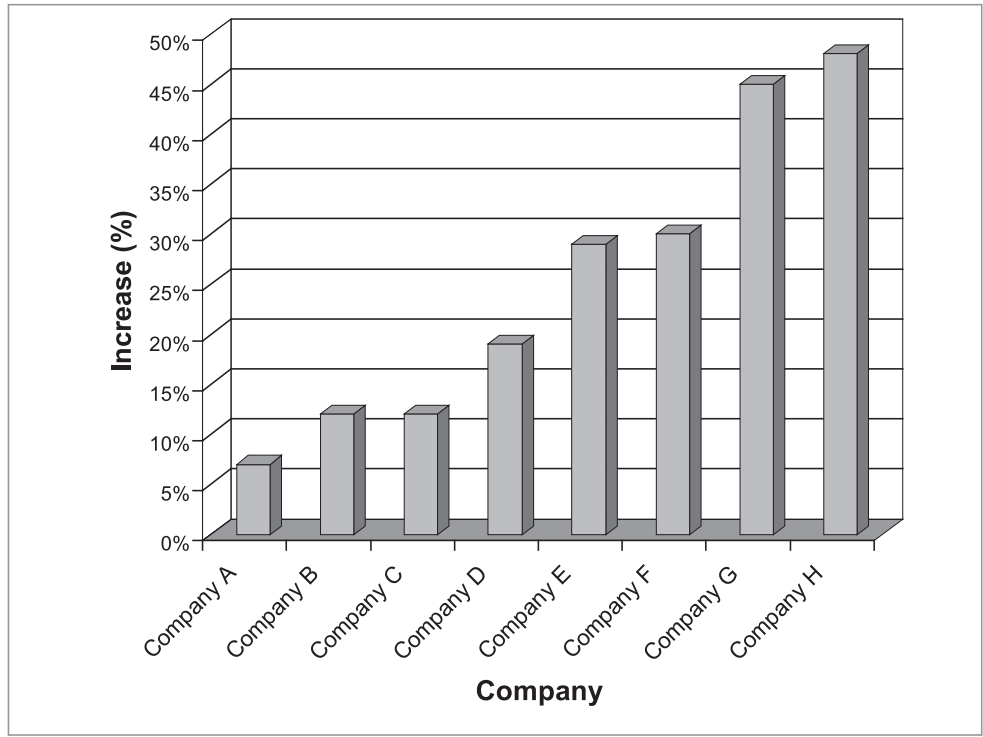

Figure 8 . Variation of project performance reported by 8 companies



Figure 9. Performance Improvements Perceived by Project Team M embers

\section{Implementation barriers}

Working in a collaborative approach, with different training actions, sharing experiences and information among the companies produces a number of benefits: development of skills for implementation, development of a healthy competition among companies that are working together, fast learning from successes and failures. For instance, companies that fail in their first attempts tend to react in a better way in order to understand the reasons of their failure and to improve their implementation process. They realize that things are possible because there is al ways a project that could do it and they can learn how to do it better the next time. Some implementation barriers identified by GEPUC with regard to the implementation of LPS and other Lean Construction tools were (Alarcon et al., 2002):

- Time: the main difficulty in the implementation, according to the participants, was the lack of time for implementing new practices in the projects that were already under way.

- Training: the second difficulty, in order of importance 
in the implementation, was the lack of training.

- O rganization: to respond adequately to the challenge of implementing the LPS, it was necessary to create or fortify some organizational elements.

- Lack of Self-Criticism: the lack of self criticism limited the capacity to learn from errors since only part of the problems were perceived.

In addition to understanding the barriers perceived during the work, it is also necessary to respond to some deficiencies of the implementation on some projects:

- Low understanding of the concepts of LPS (production units, work flow, screening, shielding, pulling).

- Low use of the different elements of LPS (M ake ready, formation of W orkable Backlog and taking of actions correctives)

- Inadequate administration of the necessary information to generate a "learning cycle" and to take corrective actions.

- Weak communication and transparency among participants of the production process (managers, administrators, foremen, etc.).

- Lack of integration of the production chain (client, suppliers of materials, subcontractors).

\section{Conclusions}

The analysis of the evidence obtained from implementation of Lean Construction practices in many projects analyzed in this paper demonstrate the effectiveness of the proposed practices and their multiple benefits:

- The LPS is an effective tool to improve reliability of planning in projects.

- Improvements in PPC are usually accompanied by a more stable and less variable performance of the PPC indicator.

- Improved PPC performance produce a shift in causes for non-compliance from internal to external causes.

- IT tools can support a more complete and standard implementation of the LPS in projects and increase the probability to achieve higher PPC performance.

- Performance improvements were observed in almost all the projects under investigation. However, performance measurement was a difficult task for the companies.

- Performance improvement impacts between $7 \%$ to $48 \%$ were reported by 8 companies that participated in the implementation program.

The experience and the results obtained have lead to the design of an implementation strategy that has produced good results. The strategy involves development of systematic training and research actions, a proactive interaction with contractor upper management and project organizations, collaboration among companies and a constant search for new ways to improve the implementation process.

Working in a collaborative approach, with different training actions, sharing experiences and information among the companies produces a number of benefits: development of skills for implementation, development of a healthy competition among companies that are working together, fast learning from successes and failures.

\section{Acknowledgements}

Support was provided by FONDEF project DOI1004 and several participating firms. We also appreciate the collaboration of the Chilean Chamber of Construction for its permanent support of the research efforts.

\section{References}

Alarcón L. F., Ashley D. B. and Cruz J. C. (2000), "The Impact of Planning Strategies on project Performance". CIB W 092 Procurement Systems Symposium, Santiago, Chile, April.

Alarcón L.F. and Calderon R. (2003), "Implementing Lean Production Strategies in Construction Companies". ASCE, Construction Research Congress 2003, Honolulu, Hawaii, USA.

Alarcón L.F. and Diethelm S. (2001), "O rganizing to Introduce Lean Practices in Construction Companies". Ninth Annual Conference of the International Group for Lean Construction (IGLC-9), August, Singapore.

Alarcón L.F., Diethelm S. and Rojo O. (2002b), "Collaborative Implementation of Lean Planning Systems in Chilean Construction Companies". Tenth Annual Conference of the International Group for Lean Construction (IGLC-10), August, Brazil.

Alarcón L.F., Grillo A., Freire J. and Diethelm S. (2001), "Learning from Collaborative Benchmarking in the Construction Industry". Ninth Annual Conference of 
the International Group for Lean Construction (IGLC9), August, Singapore.

Alarcón L.F. and Seguel L. (2002a), “D eveloping Incentive Strategies for Implementation of Lean Practices in Construction". Tenth Annual Conference of the International Group for Lean Construction (IGLC-10), August, Brazil.

Ballard H.G. (2000), The Last Planner System of Production Control, Ph.D. Dissertation, School of Civil Engineering, The U niversity of Birmingham, U.K., May, 192 pp. Ballard G. and Howell G. (1998), "Shielding Production: An Essential Step in Production Control". Journal of Construction Engineering and Management, ASCE, Vol. 124, No. 1, January/February 1998, pp. 11-17. Calderón R. (2004), Plan Control: Support System for Production Planning and Control in Construction. Master Thesis, School of Engineering, U niversidad Católica de Chile.

Choo H.J. and Tommelein I.D. (2001), "Requirements and Barriers to Adoption of Last Planner Computer Tools". N inth Annual Conference of the International Group for Lean Construction (IGLC-9), 6-8 August, Singapore.

Choo H.J., Tommelein I.D., Ballard G. and Zabelle T.R. (1999), "W orkPlan: Constraint-Based Database for Work Package Production Scheduling". Journal of Construction Engineering and Management, ASCE, Vol. 125, No. 3, May/June, pp. 151-160. Koskela L. (2000), An Exploration Towards a Production Theory and its Application to Construction. VTT Publication 408. VTT Building Technology, Espoo, Finland. 